\title{
Experimental Study on Self Compacted Concrete Mix Using Admixtures and Accessing its Performance By Comparing with Conventional Concrete (M25)
}

\author{
S .Vivek ${ }^{1}$, R. Sulekha ${ }^{2}$ and G. Sri Harini ${ }^{3}$ \\ ${ }^{1}$ Assistant Professor, ${ }^{2 \& 3}$ Student, Department of Civil Engineering, \\ Sri Ramakrishna Engineering College, Coimbatore, Tamil Nadu, India \\ E-Mail: vivek.sivakumar@srec.ac.in
}

\begin{abstract}
The self compacted concrete is an innovative product in civil engineering field of India. The necessity of this product was felt by civil engineers to overcome in the issue of workmanship, in structural concreting of heavily reinforced sections in execution of concrete. The introduction of SCC in the precast concrete industry was successful, with regard to application in situ; the development is slower because of the sensitivity of the product.The development of concrete that can be compacted in to every corner of a formwork by means of its own weight and without vibration is reviewed.SSC was developed to achieve durable concrete structures.This type of concrete has used by large construction companies.In recent years SSC has gained wide use for placement In reinforced concrete structures with difficult casting conditions. Sludge is a major issue since the they are the obtained from sewage and industrial waste where it causes many problems, so it can be used as admixture to the concrete because it attains more strength. In this paper, the mechanical properties of SCC in comparison to conventional concrete and concrete using sludge were discussed. The compressive strength results of hardened concrete showed that SCC gained strength slowly compared to theconventional cement concrete due to the presence of admixture and it's 28 days strength was lower than conventional cement concrete ,but SCC eventually had potentials of higher strength beyond 90 days. Finally the effect of water cement ratio on the plastic properties of SCC was quite negligible compared to conventional method.

Keywords: Concrete, self-compactingconcrete, compressive strength, water cement ratio, plastic properties, hardened concrete, etc
\end{abstract}

\section{INTRODUCTION}

The introduction of the "modern" self-compacting concrete (SCC) is associated with the drive towards better quality of concrete pursued in Japan in late $1980^{\circ \mathrm{ec}} \mathrm{s}$, where the lack of uniform and complete compaction had been identified as the primary factor responsible for poor performance of concrete structures. There were no practical means by which full compaction of concrete on a site was ever to be fully guaranteed, instead, the focus therefore turned onto the elimination of the need to compact, by vibration or any other means. This led to the development of the first practicable SCC by researchers Okamura \&Ouchi [1] at the University of Tokyo.The SCC, as the name suggests, does not require to be vibrated to achieve full compaction. These include an improved quality of concrete and reduction of on-site repairs, faster construction times, lower overall costs, facilitation of introduction of automation into concrete construction. The composition of SCC mixes includes substantial proportions of fine-grained inorganic materials; this offers possibilities for utilization of "dusts", which are currently waste products demanding with no practical applications and which are costly to dispose of. Self-compacting concrete (SCC) is a flowing concrete mixture that is able to consolidate under its own weight.The highly fluid nature of SCC makes it suitable for placing in difficult conditions and in section with congested reinforcement. Use of SCC can also help minimize hearingrelated damages on the worksite that are induced by vibration of concrete. Another advantage of SCC is that the time required to place large sections is considerablyreduced.When the construction industry in Japan experienced a decline in the availability of skilled labor in the 1980s, a need was felt for a concrete that could overcome the problems of defective workmanship. This led to the development of self-compacting concrete, primarily through the work by Okamura. A committee was formed to study the properties of self-compacting concrete, including a fundamental investigation on workability ofconcrete, which was carried out by Ozawa et al. at the University of Tokyo. The first usable version of selfcompacting concrete was completed in 1988 and was named "High Performance Concrete", and later proposed as "Self-Compacting High Performance Concrete".

Current studies in SCC, which are being conducted in many countries, can be divided into the following categories:

1. Use of rheometers to obtain data about flow behavior of cement paste and concrete,

2. Mixture proportioning methods for SCC,

3. Characterization of SCC using laboratory test methods,

4. Durability and hardened properties of SCC and their comparison with normal concrete, and

5. Construction issues related to SCC.

These will be relevant to the immediate needs. In addition, the following questions also need particularattention, from a long-term perspective:

1. Development of mixture design guideline tables similar to those for normal concrete, 
2. A shift to more 'normal' powder contents in SCC, from the existing high powder mixtures,

3. Better understanding of the problems of autogenous and plastic shrinkage in SCC, and

4. Development of site quality control parameters such as in 'all-in-one', acceptable tests.

The Self Compacting Concrete is an innovative concrete that does not require vibration for placing and compaction. It is able to flow under its own weight, completely filling formwork and achieving full compaction, even in the presence of congested reinforcement. The hardened concrete is dense, homogeneous and has the same engineering properties and durability as traditional vibratedconcrete.It is environmental-friendly, as industrial wastes are used and concreting is noise-free. It Reduced equipment costs as no vibration are required. It reduced manpower (example- against 150 nos. for normal concreting, 50 nos. for SCC were used in one of the sites.).Shortened construction time (Eg-Against $15 \mathrm{hrs}$. for normal concreting, 11 hrs.For SCC.). Early strength gain. Reduced formwork costs as no. of repetitive uses with SCC are more than with normal concrete (50\% roughly more.). Denser reinforcement possible. More innovative design, more complex shape, thinner section, etc are possible. Reduced bleeding, proper compaction even in congested areas, no honeycombing etc. Safe working environment is possible due to the elimination of manual labour (vibrating operator, mason etc.) for compaction and finishing works. Fewer defects and hence reduced remedial work. Improved durability. Easier placing, better surface finishing.

\section{PROPERTIES OF SELF COMPACTING CONCRETE}

\section{A. Decreased Permeability}

Increased density and long term pozzolanic action of fly ash, which ties up free lime, results in fewer bleed channels and decreases permeability.

\section{B. Increased Durability}

Dense fly ash concrete helps keep aggressive compounds on the surface, where destructive action is lessened. Fly ash concrete is also more resistant to attack by sulfate, mild acid, soft (lime hungry) water, and seawater. Reduced Sulfate

\section{Attack}

Fly ash ties up free lime that can combine with sulfate to create destructive expansion. Reduced

\section{Shrinkage}

The largest contributor to drying shrinkage is water content. The lubricating action of fly ash reduces water content and drying shrinkage. Sludge must be treated or stabilized to be safe for use or dispose. Worldwide, wastewater sludge is disposed by different methods. The most common methods of disposal depend on land application, landfill or incineration. Landfills option can be used carefully due to high costs and risk materials in sludge which may contaminate surface and ground water. Use of the incineration method to dispose sludge reduces only sludge volume. The remaining ash would still needed to be disposed in a land fill. The incineration process requires large capital investment and expensive safeguards against pollution. Large quantities of sludge are also used in agriculture field as composts. This option faced a problem which makes them unsuitable. This problem came from the existence of toxic materials in some sludge types [5]. Therefore, there is an increasing need for exploring new fields of sludge disposal. One of these new fields is to use dry sludge as an additive material to concrete mixes or using sludge ash that result from incineration process as a replacement material to cement.

\section{OBJECTIVE}

1. To find the hardened concrete properties of selfcompacting self-cured concrete with cornplast SP 430.

2. To have an idea about self-compacting self-curing concrete.

3. To find the hardened concrete properties using SP and mineral.

4. To have an idea about making procedure of selfcompacted self-cured concrete.

5. To find fresh properties of SCC - filling ability and passing ability - for mix design purposes in the lab.

6. To compare compressive strengths of concrete using different admixtures with conventional concretes

\section{SCOPE OF THE STUDY}

1. This concrete having self-compact ability with which it can be placed in the every corner of formwork without vibration causing no segregation.

2. The performance evaluation method of fresh SelfCompacting Concrete widely differs depending on whether vibration is given to the concrete during placing.

3. Self-Compacting Concrete that can be placed without any external forces other than gravity.

4. Due to less vibration is needed, SCC can be used in precast product plants.

5. It helps to reduce the number of workers required at the construction site.

6. In precast product plants as well, SCC is highly effective in reducing the noise as it requires no vibration.

\section{MATERIALS AND METHODS}

\section{A. Cement}


Cement is a binder, a substance used in construction that sets and hardens and can bind other materials together. The most important types of cement are used in the components in the production of mortar in masonry, and of concrete, which is a combination of cement and an aggregate to form strong building materials. Concrete produced from Portland cement is one of the most versatile construction materials available in the world.

\section{The Role of Aggregate in Concrete Countertop Mix Formulas}

Aggregate in concrete is a structural filler, but its role is more important than what that simple statement implies. Aggregate occupies most of the volume of the concrete. It is the stuff that the cement paste coats and binds together. The composition, shape, and size of the aggregate all have significant impact on the workability, durability, strength, weight, and shrinkage of the concrete. Aggregate can also influence the appearance of the cast surface, which is an especially important consideration in concrete countertop mixes.

When selecting the most appropriate aggregate for a particular concrete mix, here are the key factors to consider:

\section{Materials used for Preparing Aggregate}

Most natural stones and crushed rock are appropriate for use in concrete. Commonly used stones are quartz, basalt, granite, marble, and limestone. If a concrete countertop is going to be ground with diamond tooling, the aggregate will show, so aesthetics also affect the choice of aggregates.

Problems arise with soft, reactive or weak stone or rock. Lightweight aggregates, a topic for another discussion, are also used in concrete.

\section{Size}

Aggregate size and gradation are the most important factors when selecting aggregate. Aggregate can be large or small, from fist-sized rocks to fine sand. Aggregates larger than $1 / 4$ inch are classified as coarse aggregate, while anything smaller than $1 / 4$ inch is termed fine aggregate. As a general rule, the largest aggregate should be no greater in diameter than one-third the depth of the slab, or one-fifth the smallest dimension of the form. For example, the largest piece of

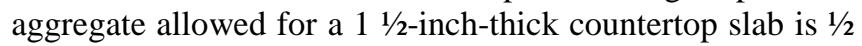
inch. Generally coarse aggregate is blended with finer aggregates (such as sand) to fill in the spaces left between the large pieces and to "lock" the larger pieces together. This reduces the amount of cement paste required and decreases the amount of shrinkage that could occur.

\section{Shape}

Aggregate shape influences strength, but has more of an immediate impact on the workability of the plastic concrete.
Rough, angular particles pack tighter, have more surface area, and have greater interparticle friction than smooth, rounded particles, which reduces workability. Angular particles also require a bit more cement paste to coat them than rounded particles. Therefore, mixes containing them will require a slightly higher cementitious content.

\section{Graduation}

In general, coarse aggregates tend to be about 10 times larger than the fine aggregates in concrete, but the range of sizes could be greater than that in certain circumstances. As shown in the figure, there are three typical range categories:

1. Well-graded aggregate has a gradation of particle sizes that fairly evenly spans the size from the finest to the coarsest. A slice of a core of well-graded aggregate concrete shows a packed field of many different particle sizes.

2. Poorly graded aggregate is characterized by small variations in size. This means that the particles pack together, leaving relatively large voids in the concrete.

3. Gap-graded aggregate consists of coarse aggregate particles that are similar in size but significantly different in size from the fine aggregate. A core slice of gap-graded concrete shows a field of fine aggregate interspersed with slightly isolated, large aggregate pieces embedded in the fine aggregate.

Typical aggregate gradations are shown in the drawing below:

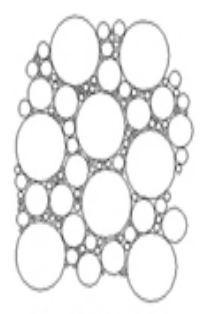

Well Graded

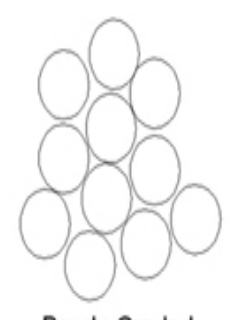

Poorly Graded

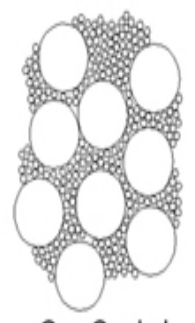

Gap Graded
Fig.1 Typical aggregate gradations

Poorly graded concretes generally require excessive amounts of cement paste to fill the voids, making them uneconomical. Gap-graded concretes fall in between wellgraded and poorly graded in terms of performance and economy. Gap-graded concrete is a viable gradation, but not optimal.Well-graded aggregates are tricky to proportion. The goal of aggregate proportioning and sizing is to maximize the volume of aggregate in the concrete (and thus minimize the volume of cement paste) while preserving strength, workability, and aesthetics. This balances the proportions of each so there are just enough of each size to fill all the voids, while preserving workability and castsurface quality.Note that aggregate gradation is particularly important in cast in place concrete countertop mixes. 


\section{B. Motar Concrete}

Concrete made with just fine aggregate (or sand) is known as mortar concrete. Like the mortar used for brick and concrete block construction, which is simply made with mortar cement and sand, mortar concrete has no coarse aggregate in it, so a ground finish will have a fine-grained appearance. Mortar concrete is commonly used in concrete countertop mixes, since the surface finish is so important.Even with an all-sand mix, aggregate gradation is still an important factor to consider and affects strength, workability, and aesthetics. It is always preferable to have some particle size variation rather than absolute uniformity because the interparticle void volume will be lower than with uniform particle sizes. While it is possible to blend different sands of different sizes together in a fashion similar to graded aggregates, generally only one type of sand is used.

Most sand, especially bulk or bank-run sand, already has a particle size distribution that has some variation to it.In order to achieve adequate workability, the cement paste volume must be high enough to encapsulate all of the aggregate particles and to provide some workability while the concrete is fresh. Therefore, mortar concrete tends to have a high cement content.Aggregate gradation, whether in a mortar concrete or a traditional concrete mix, involves tradeoffs between strength and workability and is always a delicate balance. Understanding the implications of aggregate gradation is especially important when creating a from-scratch mix and will ultimately help you produce a better concrete countertop.

\section{Fine Aggregate}

Fine aggregate is one of the essential components in concrete and significantly influences the material properties. As parts of natures, physical characteristics of fine aggregate are highly relevant to its behaviors in concrete. The most of previous studies are mainly focused on the physical properties of coarse aggregate due to the equipment limitations. In this paper, two typical fine aggregates, i.e. river sand and crushed rock, are selected for shape characterization. The new developed digital image analysis systems are employed as the main approaches for the purpose. Some other technical methods, e.g. sieve test, laser diffraction method are also used for the comparable references. Shape characteristics of fine aggregates with different origins but in similar size ranges are revealed by this study. Compared with coarse aggregate, fine grains of different origins generally have similar shape differences. These differences are more significant in surface texture properties, which can be easily identified by an advanced shape parameter: bluntness. The new image analysis method is then approved to be efficient for the shape characterization of fine aggregate in concrete.

\section{Coarse Aggregate}

Construction aggregate, or simply "aggregate", is a broad category of coarse to medium grained particulate material used in construction, including sand, gravel, crushed stone, slag, recycled concrete and geosynthetic aggregates. Aggregates are the most mined materials in the world. Aggregates are a component of composite materials such as concrete and asphalt concrete; the aggregate serves as reinforcement to add strength to the overall composite material. Due to the relatively high hydraulic conductivity value as compared to most soils, aggregates are widely used in drainage applications such as foundation and French drains, septic drain fields, retaining wall drains, and road side edge drains. Aggregates are also used as base material under foundations, roads, and railroads. In other words, aggregates are used as a stable foundation or road/rail base with predictable, uniform properties (e.g. to help prevent differential settling under the road or building), or as a low-cost extender that binds with more expensive cement or asphalt to form concrete.

\section{E. Sludge}

Sewage sludge is a by-product. It is one of final products of wastewater treatment a sewage treatment plants. The wastewater treatment plants (WWTPs) equipments concentrate impurities in wastewater into solid form and then separate these solid from liquid. The solid remain is known by sludge [6].The source of sludge in wastewater treatment plant varies according to plant type and its method of operation. The main sources of sludge are primary sedimentation basins and secondary clarifiers.

A small amount comes from chemical precipitation, screening, grinde and filtration device So, sludge may be classified according to its source, wastewater source, to three main groups as following:

a) Sludge originating from treatment of urban wastewater which involves domestic wastewater or the mixture of domestic wastewater with industrial wastewater and/or run off rainwater.

b) Sludge originating from treatment of industrial wastewater, such as water used in industrial process.

c) Sludge originating from water treatment before its consumption for drinking. The generated sludge of this type is lower than the sludge generating from wastewater treatment process.

\section{F. Admixture}

Admixtures are the substances which are added in the concrete in addition to its ingredients to enhance its performance. Such as to accelerate or retard setting and hardening, to improve workability, increasestrength, durability, decrease Permeability, to impart other desired Properties. 


\section{G. Admixture Used}

Conplast SP430: Conplast SP430 is a Chloride free super plasticing admixture based on selected sulphonated naphthalene Polymers.It is supplied as a Brown Solution which instantly disperses in water.Conplast SP430 disperses the fine particles in the concrete mix enabling the water content of the concrete to perform more effectively. The very high levels of water reductions possible allow major increase in strength to be obtained.

Typical Properties
1) Appearance
: Brown Liquid
2)Specific Gravity
$: 1.18 @ 25^{\circ} \mathrm{C}$
3)Chloride Content
: NIL to BS5075/BS:EN934
4) Air Entrainment : Less than $2 \%$ additional air is entrained at normal dosage.

\section{H. Methodology}

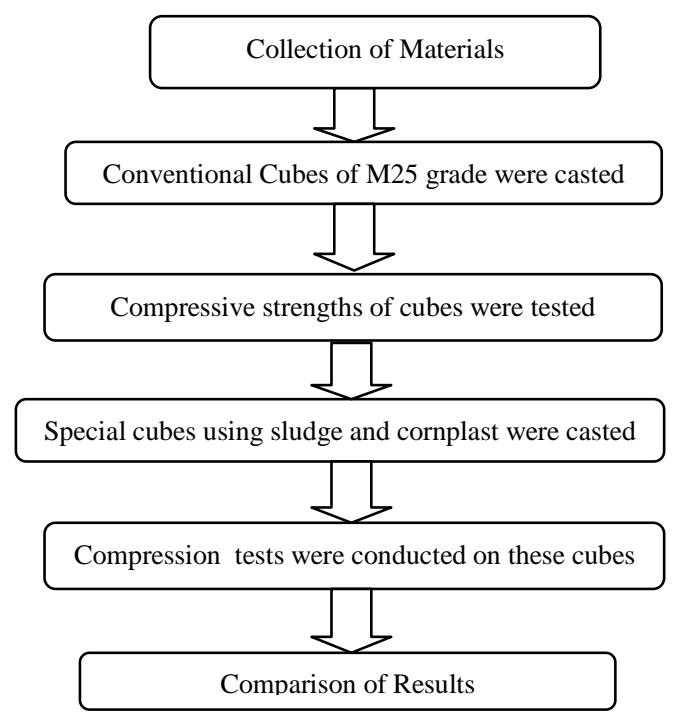

Fig. 2 Methodology

\section{RESULTS AND DISCUSSIONS}

\section{A. Compressive Strength Comparisons}

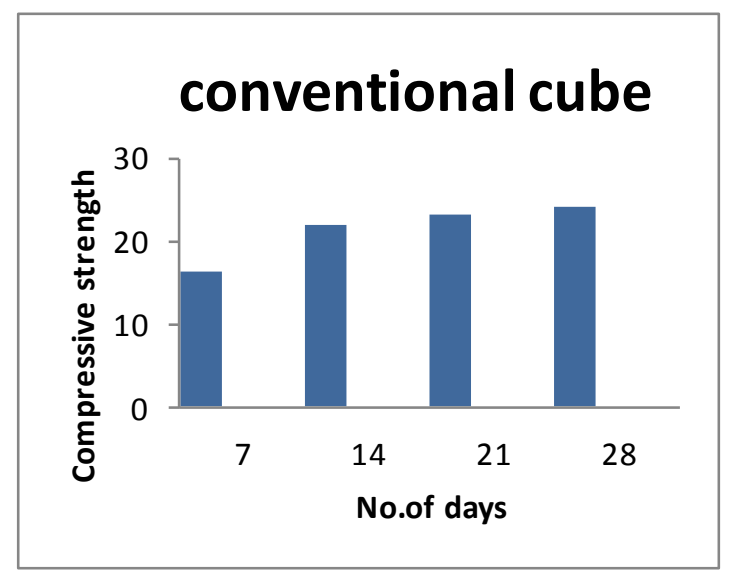

Fig. 3 Compressive Strength of Conventional Concrete

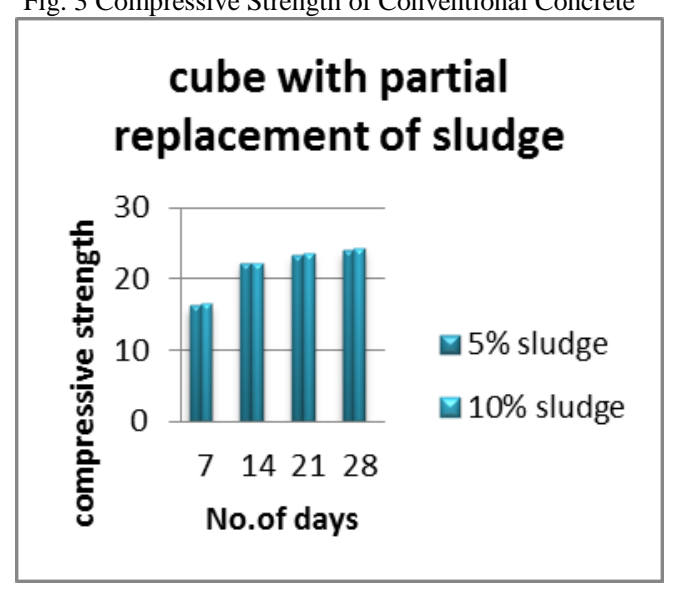

Fig. 4 Compressive Strength of Conventional Concrete with Additional Sludge

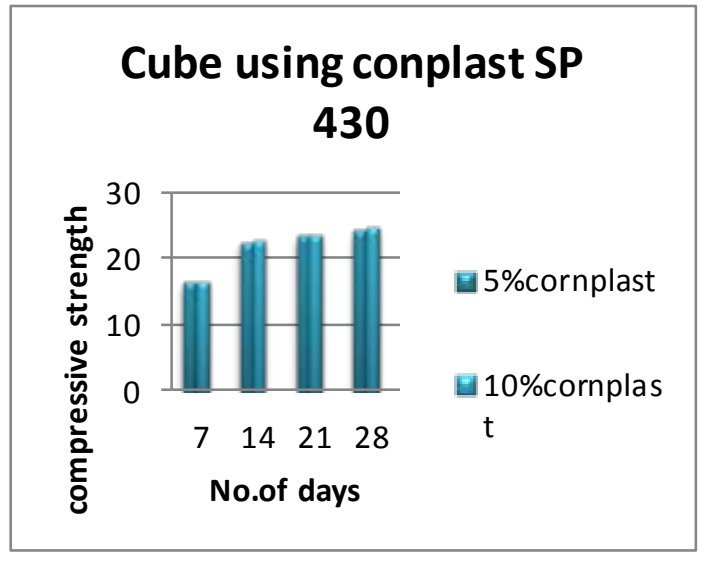

Fig. 5 Compressive strength of conventional concrete with admixture conplast SP 430 


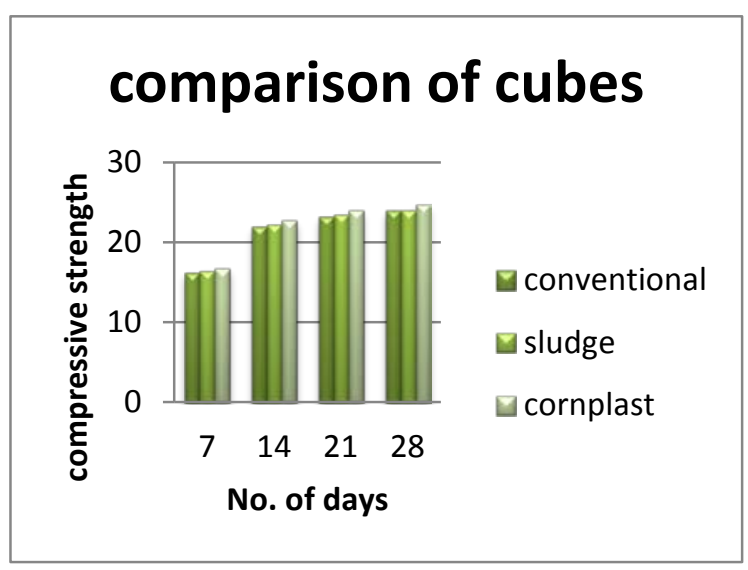

Fig. 6 Comparison of Compressive Strength of Conventional Concrete With All The Above Mentioned Combinations

Fig. (3) represents the compressive strength of the conventional concrete, which shows the gradual increase in the compressive strength.

Fig. (4) represents the compressive strength of the concrete cubes with partial replacement of fine aggregate by sludge which shows the gradual increase in the compressive strength.

Fig. (5) represents the compressive strength of the concrete blocks added with the admixture conplast sp 430, which shows the gradual increase in the compressive strength Fig. (6) represents the comparision of compressive strengths of the Fig $(1,2,3)$.

\section{CONCLUSION}

It is evident from the experimental results that the compressive strength of the concrete with partial replacement of fine aggregate by sludge is greater than that of the conventional concrete.hence it is conveying that the compressive strength slightly increases with the increase in percentage of Conplast SP 430 and increases with the increase in percentage of Sludge.Though there is a reduction in strength due to the use of Conplast SP 430 and increase in strength due to the use of Sludge in concrete, as a replacement of cement, it is encouraged because it plays a significant role in reducing the environmental hazards. The compressive strength of concrete with conplast as an admixture also showed good result.

\section{REFERENCES}

[1] Okamura, "Self Compacting Concrete", Journal of Advanced Concrete Technology, Vol. 1, No. 1, pp. 5-15, April 2003.

[2] Aijaz Ahmad Zende and R. B. Khadirnaikar "An Overview of the Properties of Self Compacting Concrete”, IOSR Journal of Mechanical and Civil Engineering, e-ISSN: 2278-1684, p-ISSN: 2320 -334X, 2014, pp. 35-43.

[3] "Specification and Guidelines for Self-Compacting Concrete", EFNARC, Feb 2002.

[4] S. Venkateswara Rao, M. V. SeshagiriRao and P. Rathish Kumar "Effect of Size of Aggregate and Fines on Standard and High Strength Self Compacting Concrete" Journal of Applied Sciences
Research, Vol. 6, No. 5, pp. 433-442, 2010.

[5] B. Mahalingam and K. Nagamani, "Effect of processed fly ash on fresh and hardened properties of self-compacting concrete", International Journals of Earth Science and Engineering, ISSN 09745904,Vol. 4, No. 5, 2011.

[6] S. Kennouche, A. Zerizer, A. Benmounah and B. Hami, "Formulation and characterization of self compacting concrete with silica fume", Journal of Engineering and Technology Research, Vol. 5, No. 5, pp. 160-169, 2013.

[7] V. Mallikarjuna Reddy, M. V. Seshagiri Rao, P. Srilakshmi and B. Sateesh Kumar, "Effects of W/C ratio on workability and mechanical properties of High strength self compacting concrete", International Journal of Engineering Research and Development, Vol. 7, Issue 1, pp. 06-13, 2013.

[8] N. Krishna Murthy, A. V. Narasimha Rao, Ramana, I. V. Reddy and M. Vijaya Sekhar Reddy, "Mix design procedure for self-compacting concrete”, IOSR Journal of Engineering, Vol. 2, Issue 9, pp. 33-41, 2012.

[9] Zoran Grdic, Iva Despotovic and Gordan Toplicic, "Properties of self-compacting concrete with different types of additives", Architecture and Civil engineering, Vol. 6, No. 2, pp. 173-177, 2008.

[10] Fareed Ahmed Memon, Muhd Fadhil Nuruddin and Nasir Shafiq, "Effects of silica fume on fresh and hardened properties of fly ash based self-compacting geopolymer concrete", International Journal of Minerals, Metallurgy and Materials, Vol. 20, No. 2, pp. 205, 2013.

[11] S. Dhiyaneshwaran, P. Ramanathan, L. Baskar and R. Venkatasubramani, "Study on durability characteristics of selfcompacting concrete with fly ash", Jordan Journal of Civil Engineering, Vol. 7, No. 3, 2013.

[12] B. Mahalingam and K. Nagamani, "Effect of processed fly ash on fresh and hardened properties of self-compacting concrete", International Journals of Earth Science and Engineering, ISSN 09745904, Vol. 04, No. 05, 2011.

[13] S. Kennouche, A. Zerizer, A. Benmounah and B. Hami, "Formulation and characterization of self compacting concrete with silica fume", Journal of Engineering and Technology Research, Vol. 5(5), pp. 160169, 2013.

[14] V. Mallikarjuna Reddy, M. V. Seshagiri Rao, P. Srilakshmi and B. Sateesh Kumar, "Effects of W/C ratio on workability and mechanical properties of High strength self compacting concrete”, International Journals of Engineering Research and Development, Vol. 7, Issue 1, pp. 06-13, 2013. 